\title{
PROTOCOLO Y ARTE: Una mirada creativa
}

\author{
Marta Barrio Narro
}

\section{Resumen}

Protocolo y Arte parecen dos disciplinas dispares. No obstante, podemos encontrar una coexistencia entre ambos. El Protocolo es la regla ceremonial diplomática ejercida aplicada entre los hombres y establecida por costumbre. Hombre y Arte son inseparables. La creación artística es una función esencial del ser humano. En palabras de René Huyghe: “no hay arte sin hombre, pero quizá tampoco hombre sin arte"

\section{Palabras clave}

Protocolo - Historia del Protocolo - Protocolo y Arte - Arte - Historia de Arte

\section{Abstract}

Protocol and Art seem to be two unlike disciplines. Nevertheless, we can find a coexistence among both. Protocol is the diplomatic ceremonial rule applied among men and established by custom. Man and Art are inseparable. The artistic creation is an essential function of the human being. In words of René Huyghe: "there is not art without man, but perhaps neither man without art”

\section{Key words}

Protocol - History of Protocol - Protocol and Art - Art - History of Art 


\section{El protocolo}

\subsection{Origen del Protocolo}

El término protocolo, procede del latín "protocollum", que a su vez procede del griego (en griego deviene de protos, primero y kollom, pegar, y se refiere a la primera hoja pegada con engrudo). En su significado original, venía a decir que "protocollum" era la primera hoja de un escrito. La primera hoja en la que se marcan unas determinadas instrucciones. Esta definición marca el inicio de lo que más tarde será el verdadero significado del término protocolo.

Pero otros autores, como Escriche, indican como origen vocablo que viene del griego, protos viene de primero en su línea y de origen latino collium o collatio que significaría cotejo. Según el diccionario de la Real Academia Española de la Lengua, entre otros significados, protocolo es: la regla ceremonial diplomática o palatina establecida por decreto o por costumbre.

Algunos historiadores indican que existían términos y expresiones protocolarias en documentos tan importantes como el Código de Hammurabi, en los jeroglíficos del antiguo Egipto y en otras muchas referencias escritas.

Si algo ha hecho evolucionar al hombre, amén de los inventos, esto ha sido la educación. Desde los tiempos más remotos se conoce la existencia de pautas sociales y normas de comportamiento. Desde que el hombre está sobre la tierra siempre ha tenido ciertas formas de comportamiento ante determinados eventos. Aunque todas estas reglas las encontramos repartidas a lo largo de toda la historia, hay un hecho definitivo y claro que nos da un punto de partida importante: la creación de la corte. Esto dará un auge definitivo a las buenas maneras.

La nobleza, se comentaba en esa época, no se lleva solamente en la sangre sino en la forma de comportarse ante el Rey y ante el pueblo. Un hecho que debemos tener siempre presente en nuestra vida. Se puede ser rico, culto e incluso un genio, pero todos somos personas y hay que comportarse educadamente con los demás. El auge de las buenas maneras era glosado por trovadores y novelas de caballería donde se daban consejos sobre cómo ser una dama o un caballero educado.

Entre los libros publicados destacamos "El Cortesano" de Baltasar de Castiglione, un punto de referencia en el mundo de las buenas maneras. Podemos decir, que fue el primer libro con profusa información sobre el comportamiento educado. En él se hace referencia de forma detallada a muchos aspectos del protocolo de aquella época. 
Aunque muchas de la reglas queden obsoletas o deban transformarse, la buena educación nunca pasa de moda. Ser educado no es una moda, es algo inherente a nuestra condición humana. Nos hace más libres y más tolerantes.

Ahora bien, tampoco se debe abusar, y caer en la pedantería. Todos los excesos son malos. La buena educación abre muchas puertas y dice mucho de las personas. Dice una conocida frase de Talleyrand, Príncipe de Benevento: "Solo los tontos se ríen de la buena educación".

Hay que ser natural en sus modales, y no forzarlos. "Si no sabe, es mejor no fingir (puede caer en un ridículo espantoso); observe al resto de la gente como se comporta” o, lo que es lo mismo, "donde fueres haz lo que vieres", aludiendo a la capacidad de observar cómo se comportan el resto de personas.

Y, en cualquier caso, siempre es mejor preguntar que actuar por nuestra cuenta, a riesgo de hacerlo mal, pues las costumbres son muy diversas y podemos "molestar" sin darnos apenas cuenta. Lo que para algunas culturas tiene un determinado significado para otras nos parece totalmente extraño, pero no por ello debemos dejar de actuar de un modo respetuoso. Un talante abierto nos permitirá actuar en cada momento de la forma más adecuada. Precisamente el protocolo trata de aunar esfuerzos para que estos "problemas" no surjan en grandes actos o eventos con diferentes culturas y participantes.

\subsection{Historia del Protocolo.}

\subsubsection{Protocolo en la antigüedad.}

El protocolo hunde sus raíces en la Antigüedad, en Egipto, donde el carácter religioso del protocolo escrito será el rasgo esencial de este período, puesto que la norma protocolaria está en manos de los sacerdotes.

En el Gran Imperio de China, el protocolo civil tuvo un importante protagonismo en la instauración de la convivencia civil, gracias a la pronta existencia de funcionarios de protocolo, libros de protocolo, normas de protocolo.

En la Antigüedad Clásica, Grecia y Roma, el protocolo era fundamentalmente democrático, pues no ensalzaba ninguna personalidad en virtud de la importancia que Roma concedía al aspecto jurídico del protocolo.

En España tenemos que hablar de la Hispania heredada de Roma y del mundo visigótico, donde ya el protocolo tiene un componente religioso extraordinario. 
Tenemos que recurrir a la historia para entender cómo el protocolo ha evolucionado hasta definirse en la forma en que hoy organiza al poder en nuestro país.

\subsubsection{El Protocolo en España: Ayer y hoy.}

El protocolo se centraliza en los siglos de monarquía visigótica. En Toledo, los Obispos de Toledo, van a tener una gran influencia en las ceremonias de la entronización de los Reyes Visigóticos. A estos se les ungía, como en el resto de Europa, con la unción religiosa, para después celebrar el juramento de defensa de los privilegios de sus ciudadanos y la posterior coronación. Sólo así entraban a formar parte del aparato del Estado.

Al mundo europeo, los bárbaros van a traer un mismo protocolo caracterizado por este aspecto religioso, pues son conscientes de la necesidad de conectar a la autoridad elegida con Dios, es decir, de que ésta reciba el poder de Dios, para luego implantar y solemnizar ese poder ante sus súbditos, hoy ciudadanos. Los reinos que se van a suceder en España, como los Reinos de Castilla, Navarra o Aragón, marcarán una gran diferencia respecto a este protocolo.

En el Reino de Castilla no hubo una corte, ni casi normas escritas, durante este período donde lo primordial fue la reconquista que protagonizó durante siglos. Es la tradición oral la que impera en los palacios a los que va llegando la reconquista.

Esto no sucede en el Reino de Aragón, donde su proximidad y orientación al Mediterráneo y sus posiciones en Córcega, Sicilia o Atenas ejercen una gran influencia.

Los Reyes de Aragón, al encontrarse más cerca del Papado (Italia), van a vivir un renacimiento del aspecto religioso del protocolo. Hay que recordar que el protocolo más antiguo escrito es la liturgia de la Iglesia Católica y que el Soberano Pontífice posee símbolos, a través de los cuales y de su liturgia, comunica mensajes que quiere transmitir al resto de los católicos.

En Aragón, Pedro IV el Ceremonioso, escribió las ordenaciones de su casa y Corte, el modelo según el cual iban a ser coronados los Reyes en la Casa de Aragón, en Zaragoza (capital del Reino), por el Obispo de Tarragona y las normas escritas taxativas que luego se extendieron y fueron copiadas por Napoleón Bonaparte. Nos estamos refiriendo al sistema de autocoronación por la que los Reyes Aragoneses tomaban la Corona de manos del Obispo, se coronaban a sí mismos y luego a sus esposas, tal como haría Bonaparte con Josefina posteriormente.

Efectivamente, desde hace quinientos años, vivimos en nuestro país según el Uso de Borgoña, que introdujo en España Carlos V, el Emperador Carlos I de España.

La Borgoña de los siglos XIV y XV era un ducado vasallo del Rey de Francia: el tercer hijo del Rey de Francia era el Duque de Borgoña. Era un ducado pequeño que hereda una serie de territorios al 
Norte de Francia gracias a unas alianzas patrimoniales, convirtiéndose desde hace ya casi seiscientos años en el centro del poder económico europeo.

El Ducado de Borgoña, entonces ya centro económico, crea un interesante protocolo a principios del siglo XV. El Duque Felipe el Bueno de Borgoña decidió crearlo para imponer su autoridad y renombre frente a las demás Monarquías Europeas: Inglaterra, Francia, Alemania y Castilla y Aragón.

En 1548, Carlos V deseaba que su hijo Felipe lo sucediera en el Imperio. Para preparar a su hijo en un futuro cargo imperial, introdujo al Príncipe Felipe en el Uso de Borgoña. Fue el III Duque de Alba, Mayordomo Mayor del Emperador, quien le enseñaría este Ceremonial Uso de Borgoña al Príncipe Don Felipe en Valladolid. Hoy sabemos que el 15 de agosto de 1548 se le empieza a servir al Príncipe según el Uso de Borgoña.

Felipe II introdujo los primeros cambios en este protocolo. Tras viajar a los Países Bajos, decide promulgar una Pragmática de cortesías en 1586. Felipe II se sentía abrumado por las exigencias del protocolo borgoñón y lo rechazaba, por lo que dicta esta pragmática con el objetivo de poder adaptar el protocolo de Borgoña a los usos castellanos, compaginando ambas normativas y costumbres. Entre las normas que creó, podemos destacar el uso característico en nuestro país del término Señor para hacer referencia al Jefe de Estado o Rey, sustituyendo al de Alteza y frente al uso de Majestad, referido a los Emperadores.

Todos los monarcas de la Casa de Austria estaban imbuidos por este protocolo de Borgoña, cuyo mejor reflejo es el Monasterio de El Escorial. La separación de las aulas en el Palacio de El Escorial, cuya importancia aumenta según su grado de proximidad al Soberano, sigue vigente en las salas del Palacio Real y en todo nuestro ceremonial.

La Casa de Austria se distinguió siempre por su admiración hacia el protocolo de Borgoña. Felipe III se caracterizó por su inclinación por el protocolo religioso. Felipe IV supuso el momento culminante para la Monarquía Barroca Española así como el triunfo absoluto del protocolo de Borgoña. Carlos II, el último de los Reyes de la Casa de Austria, fue un esclavo del protocolo por cuan todo su comportamiento estaba regido por aquello que dictaminaba y le permitía la norma protocolaria.

Con la llegada de los Borbones, una renovadora concepción del protocolo irrumpe en el encorsetado protocolo borgoñón de Carlos I. Felipe V, junto con sus consejeros franceses, se encuentra una España endogámica, una corte encerrada en sí misma, inundada de enanos y bufones y un pueblo vestido de luto, por lo que decide cambiar el sistema de gobierno y, con él, también a las personas. La Corte francesa giraba en torno a un sistema de actos y continuidad de la vida política 
impulsada por el Soberano, donde la ceremonia y la precedencia eran ya muy importantes. La modernización del sistema de administración del Estado, a manos de Felipe V, trae a España el incipiente organigrama del Estado con la creación de la figura de los Secretarios de Estado.

Don José de Grimaldo fue el Primer Secretario de Estado y del Despacho, quien estableció unas normas escritas de protocolo en la recepción de embajadores del extranjero que aún siguen vigentes.

Esto quiere decir que las recepciones que se realizan hoy en el Palacio Real, ya se habían definido en el ceremonial de 1717.

Asimismo, la figura del Conductor de Embajadores, o Introductor de Embajadores, que entonces llegó a España y que hoy es el cargo más antiguo de la administración española, era un figura copiada, y en esto estoy de acuerdo con la Doctora $\mathrm{M}^{\mathrm{a}}$ Teresa Otero, por Felipe IV del Maestro de Ceremonias de Enrique II de Francia.

Otra de las aportaciones de la modernización puesta en marcha por Felipe V fue la paulatina desaparición del sistema procedente de los Grandes de España, clase política creada por Carlos V y que habían llegado a monopolizar los altos cargos en nuestro país y las ceremonias que en él se celebraban. Esta situación, heredada de la época de los Reyes Católicos, se prolongó hasta la etapa de Alfonso XIII. La reina Isabel la Católica había quitado el poder político y económico a la nobleza castellana, otorgándoles a cambio los cargos palatinos que se convertían en cargos hereditarios. De esta forma, son las mismas familias, desde la época de los Reyes Católicos, las que van a monopolizar los grandes cargos de Gentiles Hombres, Aposentadores, Mayordomos...

Los consejeros de Felipe V no van a eliminar totalmente a los Grandes de España pero sí que introducen a funcionarios como los Secretarios de Despacho, que van a tener un poder muy similar a aquéllos.

Con Carlos III se produjeron nuevos cambios en el ámbito del ceremonial y el protocolo. El Rey Carlos III fue el creador, en cierta manera, de la Bandera e Himno Nacionales.

El origen de nuestro himno, por lo tanto, no se encuentra en una composición musical que, como cuenta la leyenda, regalara el Rey Federico de Prusia al Conde de Aranda.

Fue una Marcha de Pífanos, convertida en Marcha de Honor por Carlos III y no reglamentada como Himno Nacional hasta mucho después. Fue Alfonso XIII el que convirtió esta Marcha Real, que se había conservado en palacio, en Himno Nacional por una disposición de 1908, en la que el maestro Pérez Casas orquesta el himno que ha estado vigente en España hasta hace cinco años. 
Carlos III creó también la Bandera Nacional o Bandera de la Armada en 1785. En un momento histórico en el que toda Europa mediterránea estaba en manos de los Borbones y se empleaba la bandera blanca con las armas del soberano de cada país en los buques de la Armada, Carlos III creó una bandera que diferenciara en la mar a sus buques y fuera fácilmente identificable. Para esta bandera, Carlos III escoge los colores rojo y amarillo, porque son los colores que mejor se distinguen en la distancia. Aunque estos tonos tenían sus antecedentes en la bandera que ondeaba en el Reino de Nápoles y en el Reino de Aragón, los motivos por los que pasan a la Bandera de la Armada fueron de carácter pragmático: poder diferenciar a los buques en la mar.

Por ello, la bandera roja y amarilla pasaría después de los buques de la Armada a los ejércitos de tierra, convirtiéndose finalmente en la Bandera Nacional. Esto no ocurrió hasta 1860, en la Guerra de África. Los diez mil soldados españoles que intervinieron en dicha guerra llevaban en sus mochilas la bandera roja y amarilla con que serían posteriormente enterrados.

De nuevo fue Alfonso XIII quien reglamentó su uso por la disposición de 1908, junto con el Himno Nacional. Alfonso XIII dispone que la Bandera Nacional bicolor ondee en los edificios públicos los domingos y los días de fiesta. Hasta entonces la Bandera sólo había ondeado en las fuerzas del ejército de tierra y en la Armada.

Ninguno de los regímenes políticos que se sucedieron en el siglo XIX introdujeron cambios en la bandera. La Segunda República lo hizo en 1931, cometiendo el error de modificar una bandera que había sido adoptada por el pueblo desde 1860. La Segunda República identificó los colores de la bandera con la Dinastía Alfonsina y los cambió por los colores republicanos.

Tras Carlos III, tenemos que hacer una referencia obligada al reinado de José Bonaparte, quien en cinco años innovó el protocolo español. En 1809, introdujo las llamadas “Etiquetas”, donde se establecía quiénes iban a ocupar cada una de las siete salas del Palacio Real, siendo estas etiquetas reglamentadas posteriormente por la Orden Real de 1908 de Alfonso XIII.

José Bonaparte suprimió las órdenes existentes en la época de Carlos III y creó una serie de disposiciones de carácter protocolario: creó la Orden Real de España, copiando la Legión de Honor, cambió el Escudo de España (que tenía el águila imperial) e introdujo por primera vez, en dicho escudo, las Armas de Navarra.

En el siglo XIX van a surgir las primeras disposiciones escritas sobre protocolo promulgadas en la Gaceta de Madrid.

Así, entre 1856 y 1861, durante el reinado de Isabel II, se escribe un organigrama del Estado en el que aparece reflejado por primera vez el poder civil. En una disposición de 1856, Isabel II 
establece la que yo llamo alternancia del poder civil y militar, de modo que en los actos presididos por un representante del poder civil, el militar estará a su derecha y viceversa.

La Primera República, vigente sólo durante once meses, derogó muchos Títulos y Honores, mantuvo la Bandera bicolor como símbolo de la Nación, pero no tuvo tiempo para introducir nuevos usos protocolarios.

El reinado de Alfonso XIII, con el que se inaugura el nuevo siglo XX, representa uno de los momentos más importantes del protocolo español. Como hemos visto, es entonces cuando se reglamenta el uso de la Bandera Nacional y el Himno Nacional y se establece la última disposición protocolaria. Se trata de la Orden del Rey de 1908 firmada por el Jefe Superior de Palacio, publicada en la Gaceta de Madrid y refrendada por el Presidente del Consejo de Ministros. Esta Orden de 1908 recoge las Etiquetas de José Bonaparte, pues en ella se establecen las siete grandes categorías de precedencias en el organigrama del Estado Español que van a ocupar las siete salas del Palacio Real. Sería la última ocasión en que estas siete categorías serían ordenadas según el Uso de Borgoña: un orden que atiende no a lo que son las personas sino a lo que habían sido sus antepasados (Cardenales, Grandes de España, Caballeros del Toisón de Oro...)

Tras la época alfonsina, durante la dictadura de Primo de Rivera, éste intentó cambiar el protocolo, pero en 1926 dicta una orden circular en la que confiesa no poder establecer unas normas de carácter general dada la dificultad y complejidad del momento histórico por el que atraviesa nuestro país. Este preámbulo refleja, a mi entender, la España de finales de los años veinte, en los que el Antiguo Régimen tenía que sucumbir ante una incipiente sociedad civil.

Fue la Segunda República la que provocó esa ruptura definitiva con el Antiguo Régimen, y también con las normas protocolarias existentes. Se cambió el Himno, la Bandera y el Escudo; se abolieron las grandes condecoraciones del Toisón de Oro, de Carlos III y la Orden de Ma Luisa; se derogaron los Títulos de Grandes de España, etc.

En 1941 el General Franco dictamina por primera vez que la Marcha Real será el Himno Nacional de España, siendo ésta la primera vez que se habla del Himno Nacional como tal. La bandera que se estableció en Burgos en 1936 fue la Bandera de la antigua Monarquía. El enfrentamiento de las banderas de cada bando durante la Guerra Civil continúa hoy día como resquicio de aquella lucha interna que dividió al pueblo español. Debido a esto, nuestro país no ha consolidado el sentimiento de pertenencia a una bandera como ha ocurrido en otros países.

El General Franco no estableció ninguna disposición de protocolo hasta el final de su gobierno en 1968. En este año, Franco promulga un reglamento llamado de Precedencias y 
Ordenación de Autoridades y Corporaciones, en el que establece un organigrama de Estado con objeto de perpetuar la situación política.

Este Reglamento de Precedencias y Ordenación de Autoridades y Corporaciones, establece ya una moderna clasificación de actos y autoridades públicas, pues delimita el ámbito de aplicación de ordenación del Estado a los actos oficiales (excluyendo los actos privados, sociales, deportivos o religiosos) y a los cargos públicos. En el año 1975, con la Transición Española, este reglamento pierde vigencia dado que han desaparecido gran parte de las autoridades de la época del General Franco y se han definido otros nuevos cargos no contemplados en él.

El caos protocolario de la época evidencia la necesidad de crear un nuevo ordenamiento de protocolo, pues emerge una de las premisas que así lo estipulan: el cambio constitucional o paso del régimen autoritario de Franco a una nueva monarquía parlamentaria.

El primer gobierno socialista de Felipe González impulsó este cambio protocolario con un nuevo Ordenamiento General de Precedencias en el Estado (Real Decreto 2099 / 1983, de 4 de agosto), donde pusimos en práctica la Constitución Española, aplicándola a una disposición escrita de rango protocolario.

Hoy día siguen vigentes en nuestro país 16 disposiciones legales que establecen normas de protocolo y que nacieron con la Constitución y perfilaron en menos de diez años. Son disposiciones sobre la Bandera, el Himno, el Escudo, los Estatutos Especiales que existen, así como los Tratamientos, Títulos y Honores.

El Ordenamiento General de 1983 es básicamente constitucional y así lo recoge su prólogo, donde se reconocen unos principios básicos referidos al establecimiento del nuevo Estado social y democrático de derecho, bajo la forma política de una Monarquía Parlamentaria. Reconocía así la nueva estructura de poderes, culminados por el Tribunal Constitucional, órgano máximo al que corresponde la interpretación última de la Constitución.

Una de las grandes aportaciones de este ordenamiento es el reconocimiento y consideración del poder de las Comunidades Autónomas, llegándose a definir dos precedencias diferentes, para su aplicación bien en actos celebrados en Madrid, como capital de España y sede de las Instituciones Generales del Estado, bien en el resto de las Autonomías. De este modo, se consigue dar primacía a la prelación, la simbología y al mensaje de las autoridades autonómicas sobre las autoridades del Estado, no sobre los poderes del Estado, en los actos celebrados en las Comunidades Autónomas, puesto que son las autoridades máximas elegidas por la propia autonomía. 
Existe un Real Decreto del seis de noviembre de 1987, la disposición de protocolo más importante después de la Constitución, donde se establece el uso de los Tratamientos, Títulos y Honores Oficiales que tanto interés suscitan.

Según esta disposición, el Jefe de Estado tendrá el título de Rey y Majestad. La Reina Consorte, mientras lo sea o permanezca viuda, mantendrá los mismos títulos: será Reina y se le llamará Majestad. Si se casara perdería todas sus prerrogativas. El Príncipe de Asturias y su esposa, la Princesa de Asturias, tendrán el tratamiento de Alteza Real y los Honores que se le reconocen en el Ordenamiento. Los hijos del Rey de España o del Príncipe de Asturias tendrán el tratamiento de Infantes de España, pero no sus maridos o consortes, que tendrán los tratamientos y honores que el Rey les conceda graciosamente.

Como hemos visto, el uso de Tratamientos, Títulos y Honores está muy circunscrito, puesto que ya no existen dentro de la Administración.

Para terminar, quisiera hacer una última observación sobre la enorme importancia del protocolo en la comunicación institucional: el protocolo es el instrumento de comunicación del poder, a través del cual el Estado transmite su mensaje, son las relaciones públicas del Estado. Es decir, es la comunicación del mensaje la que da sentido a un acto, independientemente de la perfección que se consiga en la organización de la ceremonia.

\subsection{Principios fundamentales del protocolo}

Para poder comprender mejor las materias de protocolo, vamos a ver los principios que pensamos son fundamentales en el ejercicio del protocolo:

\section{- Principio de ordenación.}

Antes de organizar un acto, este debe ser perfectamente clasificado según el tipo o naturaleza del mismo: un acto privado, oficial, público, etc. Puede ampliar información en nuestra sección de ceremonial sobre los tipos de actos.

\section{- Principio de jerarquización.}

Establecer las categorías necesarias para la correcta ubicación de elementos y personas. La jerarquización puede ser: 
Material: la que ordena símbolos e instrumentos.

$>$ Personal: la que ordena personas dentro de los espacios que se establezcan.

\section{- Principio de armonización.}

Tratar de suavizar y solucionar situaciones nuevas y desconocidas, que se nos pueden presentar en determinados actos y ocasiones.

Este principio, no es más que un "amortiguador" en las relaciones cada vez más complejas, con distintos pueblos, razas, religiones y culturas. La base de este principio de armonización es el respeto.

\subsection{Tipos de protocolo}

En palabras de D. José Antonio de Urbina, “el protocolo es aquella disciplina que, con realismo, técnica y arte determina las estructuras o formas bajo las cuales se realiza una actividad humana”. De esta manera y, entendiendo las palabras de Urbina, podemos hablar de distintos tipos de protocolo:

\section{- Protocolo estructural.}

Protocolo encargado de crear las estructuras necesarias para el correcto desarrollo de un acto a celebrar, en el que aún no interviene ningún tipo de formalidad o protocolo, propiamente dicho. Es la parte más "material" del protocolo, ya que se trata de "crear" la organización de los elementos necesarios para que el evento se desarrolle según lo previsto y de la forma más correcta posible.

\section{- Protocolo de gestión.}

Apoyo al protocolo estructural mediante el que se controla y conduce todas las acciones que se van a llevar a cabo. Es la gestión humana que tiene lugar durante el desarrollo del acto. Podríamos también definirlo, como una serie de apoyos logísticos que son necesarios para un correcto desarrollo del acto.

\section{- Protocolo de atención o asesoramiento personal.}

Especialización consistente en un desarrollo de actividades, acciones y gestiones, cuya finalidad es la atención completa de la persona o personas a nuestro cargo. 
D. Jose Antonio de Urbina, hace de este asesoramiento personal una cuarta categoría del protocolo que llama, "Protocolo de la eficacia personal".

Según afirma Marín Calahorro, “la experiencia en la práctica del protocolo demuestra que para cada acontecimiento hay que diseñar un modelo, que debe situarse en el plano de lo posible y desarrollarse con precisión y exactitud; lo que implica la subordinación del orden simbólico a la realidad del momento".

De aquí cabe deducir que el protocolo puede verse, tal y como se trata de explicar en este trabajo, desde diversos ámbitos de aplicación:

- protocolo oficial

- protocolo internacional y diplomático

- protocolo en los medios de comunicación

- protocolo en congresos y banquetes

\section{Teoría y función del arte}

\subsection{Teoría artística}

\subsubsection{La creación artística}

\section{El lenguaje artístico}

La creación artística es una función esencial del ser humano; arte y hombre son inseparables. René Huyghe escribe: “no hay arte sin hombre, pero quizá tampoco hombre sin arte”. El hombre, para transmitir sus ideas y sus sentimientos, ha creado unos códigos basados en sistemas de signos. Uno de esos códigos es el lenguaje articulado, sin el cual no sería posible el progreso, el incremento de experiencias de la especie humana; otro es el lenguaje matemático, que permite medir las dimensiones de la realidad material y fundamentar el desarrollo de todas las ciencias de la naturaleza; otro es el artístico, ya que el arte, además de una forma de conocimiento, es un lenguaje, un medio de comunicación con el que el artista expresa imágenes de la realidad física y humana, y de las vertientes del psiquismo (sentimientos, alegrías, angustias, esperanzas, sueños). 


\section{El hombre, creador de formas}

Pero el artista no se limita a la representación, lo que nos conduciría a la concepción del arte como un espejo, sino que transforma los datos de la naturaleza y los hace resplandecer en una ordenación diferente. La obra de arte descubre al ojo humano aspectos ocultos, pero que, a diferencia del trabajo del físico, no existían antes de su conocimiento sino que comienzan a existir por el trabajo del artista.

En esta dimensión creadora de los datos y de las formas visibles radica la esencia de la actividad artística. De forma categórica lo ha expresado André Malraux: "llamo artista al hombre que crea formas, ya sea un embajador como Rubens, un imaginero como Gilbert De Autun, un anónimo como el Maestro de Chartres, un iluminador de manuscritos como Limbourg, un funcionario de la corte como Velásquez, un rentista como Cézanne, un poseso como Van Gogh, un vagabundo como Gauguin; y llamo artesano al que reproduce formas, por grande que sea el encanto de su artesanía”.

\section{Capacidad de sublimación}

La prueba de la grandeza de una obra de arte se halla en su capacidad de sublimación; en el momento en que la contemplación eleva al espectador por encima de las dimensiones de su propio yo está viviendo una experiencia similar en muchos aspectos a la del místico. En palabras de Wordsworth, en 1815, "la única prueba del genio es el acto de hacer bien lo que es digno de hacerse y que nunca se ha hecho hasta entonces”. Por encima de las fronteras del espacio y del tiempo el arte aparece como un lenguaje universal en el que se expresan las dimensiones eternas del espíritu del hombre.

\section{Velázquez y el Protocolo Internacional}

“La Rendición de Breda”, obra realizada para el Salón de Reinos del madrileño Palacio del Buen Retiro, actualmente destruido; se fecharía antes del mes de abril de 1635 y representa un episodio de la Guerra de Flandes ocurrido el 5 de junio de 1625. Tras un año de sitio por parte de las tropas españolas, la ciudad holandesa de Breda cayó rendida, lo que provocó que su gobernador, Justino de Nassau, entregara las llaves de la ciudad al general vencedor, Ambrosio de Spínola. Pero Velázquez no representa una rendición normal sino que Spínola levanta al vencido para evitar una humillación del derrotado; así, el centro de la composición es la llave y los dos generales. Las tropas españolas aparecen a la derecha, tras el caballo, representadas como hombres experimentados, con sus picas 
ascendentes que consideradas lanzas por error dan título al cuadro. A la izquierda se sitúan los holandeses, hombres jóvenes e inexpertos, cuyo grupo cierra el otro caballo. Todas las figuras parecen auténticos retratos aunque no se ha podido identificar a ninguno de ellos, a excepción del posible autorretrato de Velázquez, que sería el último hombre de la derecha; al fondo aparecen las humaredas de la batalla y una vista en perspectiva de la zona de Breda. La composición está estructurada a través de dos rectángulos: uno para las figuras y otro para el paisaje. Los hombres se articulan a su vez a lo largo de un aspa en profundidad, cerrando dicho rectángulo con los caballos de los generales. La técnica pictórica que utiliza aquí el artista no es siempre la misma sino que se adapta a la calidad de los materiales que representa, pudiendo ser bien compacta, como en la capa de la figura de la izquierda, bien suelta, como en la banda y armadura de Spínola. Breda volvió para siempre a manos holandesas en 1639

\subsubsection{Naturaleza de la obra de arte}

En una obra artística inciden y se resumen una serie de componentes individuales (personalidad del artista), intelectuales (ideas de la época), sociales (clientela) y técnicos.

\section{La personalidad del artista}

En primer lugar, la obra de arte es reflejo de una personalidad creadora y de que existe una estrecha correlación entre los perfiles del creador y los de su obra. El esfuerzo por leer la personalidad de un artista a través de sus creaciones es análogo al realizado por el psicólogo clínico. En ocasiones las escuelas psicoanalíticas han intentado llevar demasiado lejos estos procedimientos de investigación. Pero por otra parte la identificación artista -arte permite conocer la personalidad de unos hombres concretos y algunos de los procesos menos visibles en la actividad creadora.

Pero no actúa el creador sin más referencia que su propio yo, antes bien el mundo exterior de la realidad visible incide sobre sus sentidos e informa sus creaciones de manera inevitable. Si el arte es un lenguaje, los signos codificados deben ser entendidos por el espectador.

\section{Las ideas intelectuales de la época}

Sobre estos factores visibles con frecuencia se superponen elementos intelectuales, el mundo de pensamientos y sentimientos que impregnan la época en que el artista trabaja. En la plástica románica se percibe un distanciamiento de la realidad, una postura antinaturalista, y ningún artista en los siglos XI y XII se afana en conseguir que sus tallas o las figuras de sus frescos sean calcos de lo 
que sus ojos ven. De vez en cuando el vigor del elemento mental proporciona a la obra un sentido de anticipación; es cuando decimos que el artista se adelanta a su época y defiende fórmulas de sensibilidad que sólo comparte la posteridad.

\section{Las circunstancias sociales}

Las circunstancias sociales inciden también en unos hombres que no viven aislados de los demás. En nuestra época el comprador es, con frecuencia anónimo; pero en otros tiempos trabajaba por encargo de una clientela, con lo que los valores, o al menos las necesidades, de los grupos sociales dominantes incidían de alguna manera en su tarea.

\section{Los conocimientos técnicos}

En la medida que la actividad artística exige destreza manual, las posibilidades y características del material sobre el que se trabaja y los conocimientos técnicos que se tienen influyen en bastantes rasgos de la obra.

La historia del arte no es acumulativa. Un estilo no supone un progreso sobre el anterior, ni el arte de un siglo implica superioridad sobre el de los precedentes, pero sí lo es en el sentido técnico, en cuanto que los medios de trabajo se van descubriendo y perfeccionando sucesivamente.

\section{Goya y el Protocolo Oficial}

“La Familia de Carlos IV” supone la culminación de todos los retratos pintados por Goya en esta época. Gracias a las cartas de la reina María Luisa de Parma a Godoy conocemos paso a paso la concepción del cuadro. La obra fue realizada en Aranjuez desde abril de 1800 y durante ese verano. En ella aparecen retratados, de izquierda a derecha, los siguientes personajes: Carlos María Isidro, hijo de Carlos IV y María Luisa de Parma; el futuro Fernando VII, hijo primogénito de la real pareja; Goya pintando, como había hecho Velázquez en Las Meninas; Doña María Josefa, hermana de Carlos IV; un personaje desconocido que podría ser destinado a colocar el rostro de la futura esposa de Fernando cuando éste contrajera matrimonio, por lo que aparece con la cabeza vuelta; María Isabel, hija menor de los reyes; la reina María Luisa de Parma en el centro de la escena, como señal de poder ya que era ella la que llevaba las riendas del Estado a través de Godoy; Francisco de Paula de la mano de su madre, de él se decía que tenía un indecente parecido con Godoy; el rey Carlos IV, en posición avanzada respecto al grupo; tras el monarca vemos a su hermano, Don Antonio Pascual; Carlota Joaquina, la hija mayor de los reyes, sólo muestra la cabeza; cierra el grupo D. Luis de 
Parma; su esposa, María Luisa Josefina, hija también de Carlos IV; y el hijito de ambos, Carlos Luis, en brazos de su madre. Todos los hombres retratados portan la Orden de Carlos III y algunos también el Toisón de Oro, mientras que las damas visten a la moda Imperio y ostentan la banda de la Orden de María Luisa. Carlos IV también luce la insignia de las Ordenes Militares y de la Orden de Cristo de Portugal. Alrededor de esta obra existe mucha literatura ya que siempre se considera que Goya ha ridiculizado a los personajes regios. Resulta extraño pensar que nuestro pintor tuviera intención de poner en ridículo a la familia del monarca; incluso existen documentos en los que la reina comenta que están quedando todos muy propios y que ella estaba muy satisfecha. Más lógico resulta pensar que la familia real era así porque, de lo contrario, el cuadro hubiese sido destruido y Goya hubiese caído en desgracia, lo que no ocurrió. El artista recoge a los personajes como si de un friso se tratara, en tres grupos para dar mayor movimiento a la obra; así, en el centro se sitúan los monarcas con sus dos hijos menores; en la derecha, el grupo presidido por el príncipe heredero realizado en una gama fría, mientras que en la izquierda los Príncipes de Parma, en una gama caliente. Todas las figuras están envueltas en una especie de niebla dorada que pone en relación la obra con Las Meninas. Lo que más interesa al pintor es captar la personalidad de los retratados, fundamentalmente de la reina, verdadera protagonista de la composición, y la del rey, con su carácter abúlico y ausente. La obra es un documento humano sin parangón. Estilísticamente destaca la pincelada tan suelta empleada por Goya; desde una distancia prudencial parece que ha detallado todas y cada una de las condecoraciones, pero al acercarse se aprecian claramente las manchas. Goya, a diferencia de Velázquez en Las Meninas, ha renunciado a los juegos de perspectiva pero gracias a la luz y al color consigue dar variedad a los volúmenes y ayuda a diferenciar los distintos planos en profundidad. Fue la primera obra de Goya que entró en el Museo del Prado, siendo valorada en 1834 en 80.000 reales.

\subsubsection{Arte y sociedad}

\section{El arte, reflejo de la sociedad}

Los interrogantes sobre la relación artista-obra de arte pueden extenderse al plano social y plantearse las conexiones sociedad-obra de arte. Fischer en 1961 intentó demostrar, mediante el análisis de las características de un estilo, la conexión entre las estructuras sociales y los rasgos estilísticos y confirmar el supuesto de que el arte otorga expresión simbólica a los pensamientos y deseos de los miembros de una sociedad. 


\section{Influencia de la sociedad en el artista}

Las lagunas en la investigación son todavía numerosas pero parece indudable que las obras de arte no son simplemente la expresión de un artista individual sino que traslucen además múltiples aspectos de una época, de una sociedad, o al menos de un grupo social o de una institución. Entre otras cosas la época no condiciona la calidad, no aclararía cómo en el seno de una misma sociedad surgen el artista genial y a su lado figuras mediocres. Hauser reconoce que la última palabra la tiene el genio individual, pero la penúltima puede estar dictada por aquellos que tienen el poder o el dinero. El artista es libre, pero sus deseos están influidos por una serie de elementos ajenos a él: encargos, gustos de la clientela, obras de otros artistas contemporáneos, circunstancias excepcionales...

Especialmente el elemento mental, las ideas y valores que nutren la creación, no aparece por generación espontánea dentro del alma del artista sino que se desarrolla en la educación y las vivencias sociales.

\section{Independencia y relación del arte y de la sociedad}

Aún aceptando que el arte es en su expresión máxima un lenguaje y que transmite no sólo contenidos individuales, ha de esquivarse cualquier paralelismo cerrado, del tipo de sociedad cultaarte rico o sistema político arcaico-arte pobre. En términos generales, el estudio del arte no debe separarse del estudio y comprensión de las sociedades. El arte es historia, no sólo técnica, y es lenguaje de una época, no sólo de un hombre.

\section{Veronés y el Protocolo en Banquetes}

“Las Bodas de Caná” constituye un característico ejemplo del gusto de la escuela veneciana por los escenarios grandilocuentes y la composición multitudinaria. Este lienzo gigantesco fue encargado al pintor para el refectorio del convento benedictino de San Giorgio en la ciudad véneta, estancia que había sido proyectada y construida por Palladio. La obra fue entregada a la comunidad a principios de septiembre de 1563 y, al parecer, ocupó al artista por espacio de todo el año precedente; los términos financieros del contrato son perfectamente conocidos: trescientos veinticuatro ducados, más la manutención y un barril de vino.

Forman esta composición más de ciento treinta figuras. La mayor parte de ellas se hallan dispuestas en la parte inferior, en torno a la mesa en que se sirve el banquete. Cristo y su madre 
ocupan la parte central, rodeados por personajes en los que el pintor representó a personalidades de la época, entre ellos Alfonso de Ávalos, marqués del Vasto (gobernador del Milanesado), Eleonor de Austria, Francisco I y María de Inglaterra, Suleimán el Magnífico (en el lado izquierdo, reconocible gracias a su turbante) y junto a él Vittoria Colonna, acompañada por el propio emperador Carlos V, que aparece de perfil, dirigiéndose a un sirviente. El grupo de músicos que se halla en primer término está compuesto, a su vez, por retratos de artistas del momento; Ticiano toca el violoncelo, el propio Veronés la viola, Tintoretto el violín y Jacopo Bassano la flauta. En pie, a su lado, puede verse a un hombre que alza su copa, el cual retrata a Benedetto, hermano del pintor. Se trata, en suma, de una representación convencional del episodio del Nuevo Testamento, incluyendo el documento histórico de la presencia de tan ilustres comensales y comparsas.

En la parte superior, tras la balaustrada, encaramados sobre las basas de las columnas, en balcones y cornisas, aparecen personajes del pueblo, toda una cohorte de servidores. Las figuras adoptan actitudes dinámicas, lo que permite al pintor ensayar variados escorzos. Como fondo, enmarcado por los suntuosos elementos arquitectónicos captados en profunda perspectiva, un celaje de azul diluido ante el que se recorta una airosa torre. Con ello consigue el autor un equilibrio compositivo, a lo que contribuye también la adopción de un sistema perspectivo multifocal, totalmente distinto del procedimiento clásico de un centro único. La visión del detalle, en el que aparecen Eleonor de Austria, Francisco I y María de Inglaterra, Suleimán y un personaje no identificado, revela por su parte una técnica de ejecución de extraordinario efectismo y economía de medios, de inusitada madurez para un pintor que contaba tan sólo en el momento de ejecutar esta obra la edad de treinta y cuatro años.

\subsubsection{Los estilos artísticos}

\section{Definición del estilo}

La palabra estilo deriva del latín stilus, punzón, que los romanos usaban para escribir; pero en griego stilo significaba columna, y como ésta era el elemento más singular y personalizado de la arquitectura, cabe decir que la palabra estilo, en su origen, significaría el modo especial de hacer literatura o arquitectura. En arte se trata de un concepto fundamental; sin él careceríamos de los elementos que distinguen a todas las creaciones de una misma época y del sentido de la evolución de las formas.

Las denominaciones surgieron de modo lento. Aunque en el siglo XVI se habla de manera poco concreta de estilos no se aplican definitivamente a las artes plásticas hasta los estudios que en 
el siglo XVIII efectúa Winckelmann del arte griego y del ulterior análisis de Herder sobre el arte gótico.

\section{El estilo y su morfología}

La idea de que en cada época una serie de rasgos comunes de tipo artístico pueden encontrarse en tan diversas manifestaciones es la base de la famosa obra de Wölfflin, Conceptos fundamentales de la historia del Arte. Esta tesis, que otorga a cada estilo una morfología, una serie de rasgos formales comunes deja sin explicar el proceso de evolución y desintegración de los estilos.

\section{Análisis biológico del estilo}

Con cierta frecuencia se ha analizado un estilo con criterios biológicos o psicológicos; la forma artística de una cultura nacería, encontraría su plenitud y finalmente degeneraría en un período de cansancio. Pero no es fácil generalizar esta secuencia.

Con las limitaciones que el encuadre del arte supone y, a pesar de las protestas de algunos creadores contemporáneos, que se sienten encasillados, el estilo permite el análisis de los elementos comunes, técnicos y de sensibilidad; ha influido en los artistas, a los que estimula la conciencia de estar integrados en un movimiento o escuela, y permite buscar en la historia del arte unas secuencias, un sentido. No exagera Hauser cuando escribe: “sin él tendríamos, todo lo más, una historia de los artistas”.

\section{Monet y el Protocolo y los medios de comunicación}

El único canal de exposición con que contaban los pintores en la Francia del siglo XIX era el Salón de París, vinculado a la Escuela de Bellas Artes, que contaba con un prestigioso jurado que seleccionaba las obras enviadas. El escándalo de 1863 - con la presentación del Desayuno en la hierba de Manet - motivó la creación del Salón de los Rechazados, que tenía más éxito entre los jóvenes creadores que el oficial al exhibir obras más modernas. Los pintores que se reunían en el Café Guerbois en torno a Manet decidieron crear un foro de exposición diferente a los oficiales, en el que pudieran mostrar sus obras todos los artistas independientes. Así surge la I Exposición de la sociedad anónima de artistas pintores, escultores y grabadores que tuvo lugar entre el 15 de abril y el 15 de mayo en las salas que el fotógrafo Nadar les prestó. Acudieron 3.500 visitantes, que se rieron de la pintura tan moderna que contemplaban. A esa exposición Monet presentó nueve cuadros, entre los que destacó esta imagen que contemplamos ya que fue la que dio nombre al grupo. El crítico 
Louis Leroy denominó a la muestra Exposición de los Impresionistas en referencia a este cuadro y de manera totalmente despectiva. Sin embargo, los integrantes de la sociedad admitieron ese nombre como denominador del grupo. Impresión, sol naciente es una imagen tomada directamente del natural por Monet en Le Havre, representando las neblinas del puerto al amanecer mientras que el sol "lucha" por despuntar, creando magníficos reflejos anaranjados en el mar y en el cielo. La sensación atmosférica domina una escena en donde las formas desaparecen casi por completo. Los colores han sido aplicados con pinceladas rápidas y empastadas, apreciándose la dirección del pincel a simple vista, resultando una imagen de enorme atractivo tanto por su significado como por su estética.

\section{BIBLIOGRAFÍA}

- Barnechea, E., Fernández, A., Haro, J. Historia del Arte. Barcelona, Ediciones VicensVives, S.A., 1992.

- Benito Sacristán, Pilar. Manual de Protocolo, Ceremonial y Actos Públicos. Barcelona, Film Ideal 2000, S.L., 1998.

- Curso Superior de Comunicación y Protocolo. Vigo, Universidad de Vigo, 2003.

- Curso de Experto en Protocolo y Ceremonial. Documentación Genérica. Madrid, Escuela Internacional de Protocolo, curso 2003-2004.

- Fernández, Fernando. El arte del protocolo. Madrid, Grupo Anaya, S.A., 2002.

- Impresionismo. New York, Hugh Lauter Levin Associates, 1991.

- Laforet, Juan José. Protocolo y Medios de Comunicación Social. Instituto Canario de Administración Pública, 1997.

- La Pintura en los Grandes Museos. Barcelona, Editorial Planeta, S.A., 1982.

- $\quad$ Los 7 pintores españoles del XIX. Madrid, Fascículos Planeta, S.A., 1982.

- $\quad$ Los Genios de la Pintura Española. Madrid, Sarpe, S.A., 1983.

- $\quad$ Marini, Maurizio. Velázquez. Madrid, Sdad. Editorial Electa España, S.A., 1999.

- Pérez Sánchez, Alfonso E. Museo del Prado. Vitoria, Ediciones Danae, S.A., 1979.

- Pérez Sánchez, Alfonso E. Velázquez. Madrid, Museo del Prado, 1990.

- Sanjuán Monforte, José Carlos. Introducción al Protocolo Oficial del Reino de España y de la Unión Europea. Madrid, Unión Eléctrica Fenosa, 2001. 
- Vilarrubias, Felio A. Tratado de Protocolo del Estado e Internacional. Oviedo, Ediciones Nobel, S.A., 1994. 